\title{
ANOMALIA ANATÔMICA DA VEIA PORTA: UMA CAUSA RARA DE IMPOSSIBILIDADE DE DOAÇÃO DO LOBO DIREITO EM TRANSPLANTE HEPÁTICO INTERVIVOS
}

\author{
ANATOMICAL ANOMALY OF THE PORTAL VEIN: A RARE CAUSE OF IMPOSSIBILITY \\ TO RIGHT LOBE DONATION IN LIVING RELATED LIVER TRANSPLANTATION
}

\author{
Alexandre Coutinho Teixeira de Freitas, TCBC-R ${ }^{1}$; Jorge Eduardo Fouto Matias, TCBC-PR ${ }^{1}$ \\ Júlio Cezar Uili Coelho, TCBC-PR²
}

\section{INTRODUÇÃO}

O transplante hepático intervivos com doador adulto vem sendo cada vez mais utilizado para o paciente que não pode aguardar anos em lista de espera por um órgão cadavérico. Descrevemos aqui o caso de um doador com anomalia anatômica da veia porta detectada no pré-operatório e do seu receptor com trombose de veia porta não detectada previamente, diagnosticada somente no per-operatório, impedindo a realização do transplante.

\section{RELATO DO CASO}

O doador era do sexo feminino, 35 anos, não-aparentado do receptor, apresentava investigação pré-operatória com ressonância magnética, arteriografia celíaca e mesentérica e análise da fase venosa (portografia) essa última mostrando anomalia da veia porta (ausência de ramo portal direito único). O receptor era do sexo masculino com 40 anos, portador de cirrose pelo vírus da hepatite $\mathrm{B}$, encefalopatia recorrente $\mathrm{e}$ síndrome hepatorenal. O ecodoppler pré-operatório era normal. Durante a laparotomia do doador confirmou-se anomalia da veia porta do tipo III ${ }^{1}$ (Figura 1) e no receptor detectou-se trombose da veia porta recanalizada impedindo sua utilização como enxerto para reconstrução venosa no doador, opção que possibilitaria o transplante ${ }^{2}$. As hepatectomias tanto do doador quanto do receptor foram abortadas.

\section{DISCUSSÃO}

As variações anatômicas da veia porta são classificadas em quatro tipos ${ }^{1}$. No tipo I ocorre o padrão considerado normal, com bifurcação do tronco principal da veia porta em ramo direito e ramo esquerdo. No tipo II há trifurcação da veia porta em ramo direito posterior, ramo direito anterior e ramo esquerdo. No tipo III o tronco principal da veia porta fornece inicialmente o ramo direito posterior seguido do ramo direito anterior e finalmente o ramo esquerdo. No tipo IV o ramo direito anterior tem origem na veia porta esquerda. Durante o transplante hepático intervivos com lobo direito, a reconstrução vascular portal no tipo I se faz através de anastomose da veia porta direita do doador no tronco da veia porta do receptor. No tipo II podemos utilizar quatro estratégias no processo de hepatectomia parcial para transplante intervivos ${ }^{2}$. A primeira opção é a sutura da parede medial da veia anterior com a parede medial da veia posterior formando um orifício único que é anastomosado no tronco da veia porta do receptor. Outra opção é a utilização de enxerto venoso cadavérico criopreservado da veia ilíaca comum e sua bifurcação na veia ilíaca interna e externa. As veias ilíacas interna e externa são anastomosadas nos dois ramos da veia porta na mesa auxiliar de cirurgia. Utiliza-se a veia ilíaca comum para a anastomose na veia porta do receptor. A terceira opção é a ressecção de segmento da veia porta do receptor englobando sua bifurcação em ramo portal direito e ramo portal esquerdo. Esses ramos direito e esquerdo são anastomosados nos ramos anterior e posterior do lobo hepático doado na mesa auxiliar de cirurgia. $\mathrm{O}$ tronco da veia porta é usado para a anastomose no remanescente da veia porta no receptor. A quarta opção é a ressecção discóide de parte da parede da veia porta englobando os dois orifícios (anterior e posterior)

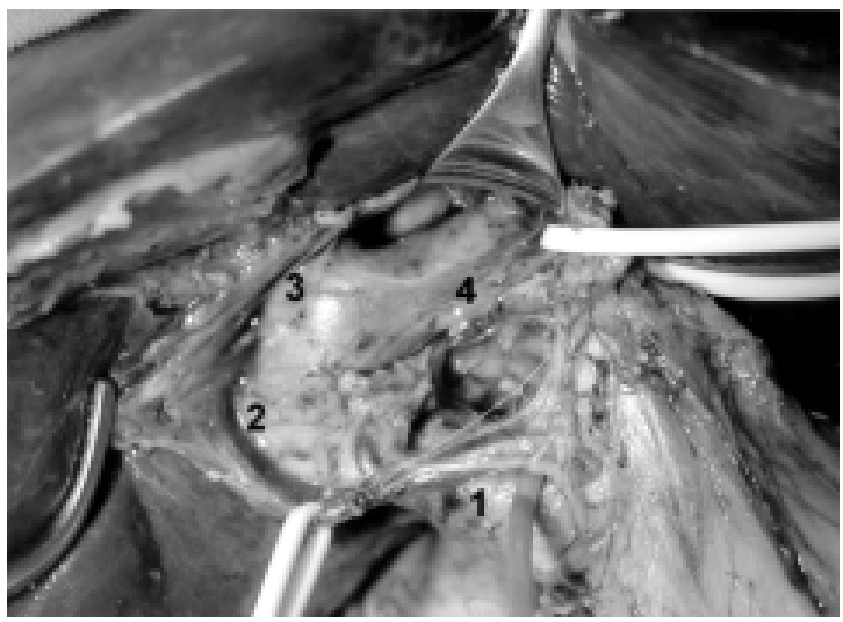

Figura 1 - Variação anatômica da veia porta (tipo III) em doador vivo de lobo direito para transplante hepático intervivos adulto. 1 -tronco da veia porta; 2 - ramo portal direito posterior; 3 -ramo portal direito anterior; 4 - ramo portal esquerdo.

\footnotetext{
1. Médico do Serviço de Transplante Hepático do Hospital de Clínicas da Universidade Federal do Paraná.

2. Professor Titular e Chefe do Serviço de Transplante Hepático do Hospital de Clínicas da Universidade Federal do Paraná. 
das veias para o lobo hepático direito. Esse segmento discóide permite a realização de uma única anastomose na veia porta do receptor. $\mathrm{O}$ defeito na veia porta remanescente do doador pode ser ressecado seguido de anastomose término-terminal ou pode ser submetido a plastia com veia ovariana ou veia jugular.

No tipo III não podemos realizar a sutura das paredes mediais dos dois vasos para a confecção de tronco único, nem realizar ressecção discóide devido a distância que separa esses dois vasos. Uma opção que não deve ser considerada é a anastomose direta dos ramos anterior e posterior do doador com os ramos direito e esquerdo da veia porta do receptor. Nessa situação ocorre desvio do eixo dos vasos com subse- qüente torção e grande possibilidade de trombose. Restam as opções de utilização de enxerto venoso criopreservado ou enxerto da veia porta do receptor. O tipo IV não deve ser usado como doador.

O doador que descrevemos nesse artigo apresentava veia porta do tipo III da classificação de Cheng et al ${ }^{l}$. Não foi possível a utilização do enxerto da veia porta do receptor devido a presença de trombose com espessamento da veia e diminuição da sua luz. Também não tínhamos a disponibilidade de enxerto venoso criopreservado. A trombose da veia porta não foi detectada no pré-operatório apesar de adequada investigação. A única opção restante foi o fechamento da cavidade do doador e do receptor e a não realização do transplante.

\begin{abstract}
Living related liver transplantation is being increasingly used for patients that can not wait for a cadaveric organ. We describe a case of a right lobe donor who had a type III portal vein anomaly. On this anomaly the portal vein gives branches first to the right posterior vein and then to the right anterior vein and the left portal vein. The recipient had portal vein thrombosis that was recognized only during the surgery. The Doppler examination performed before the operation did not detect this thrombosis. The transplant was not accomplished. Anatomical anomaly of the portal vein may be a rare cause impossibility to organ donation in living related liver transplantation (Rev. Col. Bras. Cir. 2006; 33(4): 260-261).
\end{abstract}

Key Words: Liver transplantation; Portal vein; Portal vein/abnormalities; Portal vein/anatomy \& histology; Thrombosis/ ultrasonography.

\section{REFERÊNCIAS}

1. Cheng YF, Huang TL, Lee TY, Chen TY, Chen CL. Variation of the intrahepatic portal vein: angiographic demonstration and application in living-related hepatic transplantation. Transplant Proc. 1996;28(3):1667-8.

2. Lee SG, Hwang S, Kim KH, Ahn CS, Park KM, Lee YJ, Moon DB, Chu CW, Yang HS, Cho SH, Oh KB, Ha TY, Song KW, Yu YS, Min PC. Approach to anatomical variations of the graft portal vein in right lobe living-donor liver transplantation. Transplantation. 2003;75(3 Suppl):S28-S32.
Como citar este artigo:

Freitas ACT, Matias JEF, Coelho JCU. Anomalia anatômica da veia porta: uma causa rara de impossibilidade de doação do lobo direito em transplante hepático intervivos. Rev Col Bras Cir. [periódico na Internet] 2006 Jul-Ago;33(4). Disponível em URL: http:// www.scielo.br/rcbc

Endereço para correspondência:

Alexandre Coutinho Teixeira de Freitas

Rua Ébano Pereira, 60/cj. 1901

80410-240 - Curitiba - PR

E-mail: cirurgia@alexandrectf.com.br 